\title{
How do population, general practice and hospital factors influence ambulatory care sensitive admissions: a cross sectional study
}

\author{
John Busby ${ }^{1 *}$, Sarah Purdy ${ }^{2}$ and William Hollingworth ${ }^{2}$
}

\begin{abstract}
Background: Reducing unplanned hospital admissions is a key priority within the UK and other healthcare systems, however it remains uncertain how this can be achieved. This paper explores the relationship between unplanned ambulatory care sensitive condition (ACSC) admission rates and population, general practice and hospital characteristics. Additionally, we investigated if these factors had a differential impact across 28 conditions.

Methods: We used the English Hospital Episode Statistics to calculate the number of unplanned ACSC hospital admissions for 28 conditions at 8,029 general practices during 2011/12. We used multilevel negative binomial regression to estimate the influence of population (deprivation), general practice (size, access, continuity, quality, A\&E proximity) and hospital (bed availability, \% day cases) characteristics on unplanned admission rates after adjusting for age, sex and chronic disease prevalence.

Results: Practices in deprived areas (at the 90th centile) had 16\% (95\% confidence interval: 14 to 18) higher admission rates than those in affluent areas (10th centile). Practices with poorer care continuity (9\%; 8 to 11), located closest to A\&E (8\%; 6 to 9), situated in areas with high inpatient bed availability (14\%; 10 to 18) or in areas with a larger proportion of day case admissions (17\%; 12 to 21) had more admissions. There were smaller associations for primary care access, clinical quality, and practice size. The strength of associations varied by ACSC. For example, deprivation was most strongly associated with alcohol related diseases and COPD admission rates, while continuity of primary care was most strongly associated with admission rates for chronic diseases such as hypertension and iron-deficiency anaemia.

Conclusions: The drivers of unplanned ACSC admission rates are complex and include population, practice and hospital factors. The importance of these varies markedly across conditions suggesting that multifaceted interventions are required to avoid hospital admissions and reduce costs. Several of the most important drivers of admissions are largely beyond the control of GPs. However, strategies to improve primary care continuity and avoid unnecessary short-stay admissions could lead to improved efficiency.
\end{abstract}

Keywords: Primary health care, General practice, Ambulatory care, Patient admission

\footnotetext{
* Correspondence: john.busby@qub.ac.uk

${ }^{1}$ Centre for Public Health, Queen's University Belfast, BT12 6BA, Belfast, UK

Full list of author information is available at the end of the article
} 


\section{Background}

Unplanned admissions place a tremendous strain on UK healthcare resources, accounting for $67 \%$ of hospital bed days, costing $£ 12.5 \mathrm{bn}$ annually [1] and disrupting elective care [2]. In England, they have increased by $47 \%$ over the last 15 years [1] with some arguing that their continued rise threatens to bankrupt the National Health Service (NHS) [3]. Reducing the number of unplanned admissions is a key priority [4], but is challenging due to complex hospital admission pathways.

Ambulatory care sensitive conditions (ACSCs) account for one in five unplanned admissions [5]. ACSCs are conditions where improved primary and community care could potentially prevent the need for hospital admission [6]. Substantial unexplained geographic variation in ACSC admission rates $[7,8]$ suggests reductions might be possible, however it remains uncertain how these can be achieved. Knowledge of how population (e.g. deprivation), general practice (e.g. quality) and hospital (e.g. bed availability) characteristics influence admission rates could aid the identification of poorer quality care, help redesign services, develop admission avoidance interventions, and yield financial savings for the NHS. However, currently this evidence is only available for a minority of ACSCs and is often impaired by poor generalisability, a lack of case-mix adjustment and other methodological weaknesses $[9,10]$.

In this paper we use routine data from English hospitals to examine the relationship between unplanned ACSC admission rates and several population, general practice and hospital characteristics. We determine if these factors have a differential impact across conditions.

\section{Methods}

\section{Data source and preparation}

Our study was set in the English NHS. The NHS is comprised of three broad sectors; primary care (e.g. general practitioners, pharmacists, community care), secondary care provided in hospitals, and specialist tertiary care. Primary care doctors are paid by the NHS though a weighted capitation method (based on the number and complexity of the patients under their care) with additional payments dependant on achieving quality targets through the Quality and Outcomes Framework (QOF). Hospital treatment is generally reimbursed by the NHS on a fixed payment system. Almost all services are free at the point of access.

We used the Hospital Episode Statistics (HES) admitted patient care dataset to identify admissions for 28 common (i.e. >3,000 admissions annually) ACSCs between 1st April 2011 and 31st March 2012 using ICD diagnosis codes from previous work (Additional file 1) [6]. We aggregated admissions to the level of the general practice and excluded practices with a registered population smaller than $1,000(n=68 ; 0.8 \%)$, as these are likely to represent atypical practices, or with missing covariate data $(n=26$; $0.3 \%)$ leaving 8,029 practices, with over 55 million registered patients, in the final analysis. Practices were located within all 151 Primary Care Trusts (PCTs) that, at the time of the study, commissioned care for their local populations. We investigated the effect of population (deprivation), general practice (size, access, continuity, quality, A\&E proximity) and hospital (bed availability, percentage day cases) characteristics on unplanned admission rates. Further details on the variables used within the analysis, including their potential weaknesses, are provided in Additional file 2.

\section{Association with practice and hospital characteristics}

We described the demographics of patients admitted for each condition. We estimated the relationship between unplanned ACSC admission rates and population, practice and hospital characteristics using two-level multivariate negative binomial regression models. These models include random PCT-effects which appropriately account for the clustering of practices within PCTs, adjust for latent PCT-level characteristics which could affect the demand for hospital admission, and allow the association of practice-level (e.g. access) and PCT-level (e.g. inpatient bed availability) characteristics to be estimated simultaneously. Each independent variable was scaled by the difference between a high (90th centile) and low (10th centile) practice or PCT to improve comparability across covariates (see Additional file 2 for further details).

We adjusted for differences in practice populations using a two-step process. First, we calculated the expected number of admissions using indirect standardisation (using quinary age groups and gender) and national data [11] to account for differences in the size and age-sex composition of practice populations (Additional file 3). We used negative binomial regression, and data from the QOF [12], to adjust for disparities in chronic disease prevalence among practices (atrial fibrillation, asthma, cancer, CKD, COPD, dementia, epilepsy, heart failure, hypertension, learning disability, mental health problems, obesity and stroke). Exploratory analysis revealed a nonlinear relationship with A\&E proximity for several conditions, so this were modelled using quartiles.

\section{Results}

\section{Descriptive statistics}

There were 1.77 million admissions for ACSCs accounting for 10.9 million bed days during 2011/2 (Table 1). Many admitted patients were older (mean age 56 years old), lived in more deprived communities (27\% lowest quintile), had at least one comorbidity recorded (58\%) and were admitted through A\&E (75\%). These overall results concealed substantial variation between conditions (Table 2), for example, over $30 \%$ of iron-deficiency anaemia and 
Table 1 Admission details for all ACSCs admissions

\begin{tabular}{|c|c|}
\hline Characteristics & Count (\%) \\
\hline Number of Admissions & $1,767,550$ \\
\hline Bed Days & $10,903,662$ \\
\hline Day Cases & $443,760(25.1)$ \\
\hline Mean Age & 55.6 \\
\hline 0-19 & $264,541(15.0)$ \\
\hline $20-39$ & $207,032(11.7)$ \\
\hline $40-59$ & $338,316(19.1)$ \\
\hline $60-79$ & $512,017(29.0)$ \\
\hline $80+$ & $445,644(25.2)$ \\
\hline Male & $844,537(47.8)$ \\
\hline \multicolumn{2}{|l|}{ Ethnicity } \\
\hline White & $1,495,974(84.6)$ \\
\hline Asian & $100,486(5.7)$ \\
\hline Black & $41,879(2.4)$ \\
\hline Mixed & $14,623(0.8)$ \\
\hline Missing & $114,588(6.5)$ \\
\hline \multicolumn{2}{|l|}{ Deprivation } \\
\hline 0 (Most Deprived) & $477,437(27.0)$ \\
\hline 1 & $387,099(21.9)$ \\
\hline 2 & $339,554(19.2)$ \\
\hline 3 & $302,310(17.1)$ \\
\hline 4 (Least Deprived) & $261,150(14.8)$ \\
\hline \multicolumn{2}{|l|}{ Comorbidities } \\
\hline Any & $1,032,628(58.4)$ \\
\hline Chronic obstructive pulmonary disease & $465,731(26.4)$ \\
\hline Diabetes & $288,168(16.3)$ \\
\hline Congestive heart failure & $194,692(11.0)$ \\
\hline Cerebrovascular disease & $185,824(10.5)$ \\
\hline Renal disease & $133,975(7.6)$ \\
\hline \multicolumn{2}{|l|}{ Admission Source } \\
\hline The usual place of residence & $1,671,614(94.6)$ \\
\hline Other & $94,806(5.4)$ \\
\hline \multicolumn{2}{|l|}{ Admission Method } \\
\hline Emergency: via accident and emergency & $1,326,882(75.1)$ \\
\hline Emergency: via general practitioner & $290,218(16.4)$ \\
\hline Other & $150,450(8.5)$ \\
\hline \multicolumn{2}{|l|}{ Discharge Destination } \\
\hline The usual place of residence & $1,597,060(90.4)$ \\
\hline Patient died & $80,371(4.6)$ \\
\hline Nursing home & $35,425(2.0)$ \\
\hline Other & $54,694(3.1)$ \\
\hline
\end{tabular}

ENT infection admissions originated from a GP referral, while this was the case for less than $5 \%$ of schizophrenia and alcohol-related disease admissions.
Association between unplanned ACSC admission rates and practice characteristics

For all ACSCs combined, practices located in deprived areas (at the 90th centile) had 16\% (95\% CI: $14,18)$ higher admission rates than those situated in affluent localities (at the 10th centile, Table 3). The quartile of practices closest to A\&E had 8\% (95\% CI: $7,10)$ higher admission rates than those in the furthest away quartile. Practice admission rates were highly dependent on these characteristics. For example, after adjusting for age and sex, 83\% of practices based in the most deprived quartile of areas had admission rates above the national average compared to only $15 \%$ in the least deprived areas (Fig. 1). Practices with poor care continuity (10th centile) had $9 \%$ (95\% CI: 8, 11) more admissions than those with good continuity (90th centile, Table 3 ). Practices located in PCTs with more hospital beds had higher (12\%, 95\% CI: 8, 17) admission rates, as did those with a larger proportion of day case admissions (17\%, 95\% CI: 12, 22). The association between admission rates and primary care access, clinical quality, and practice size was much smaller.

The strength of associations varied substantially across ACSCs (Table 3, Fig. 2, Additional file 4). For example, admission rates for alcohol-related diseases and COPD were more than a third higher among patients registered at practices in deprived areas while differences of less than $8 \%$ were found for several ACSCs including hypertension and migraine / acute headache. Improved continuity of primary care was most strongly associated with lower unplanned admission rates for chronic conditions such as hypertension, COPD, peripheral vascular disease and iron-deficiency anaemia. Proximity to A\&E was most strongly associated with high admission rates for mental-health conditions, alcohol-related diseases, and several conditions where patients were regularly admitted for less than a day (e.g. dental conditions, asthma, constipation).

Areas with increased bed availability had particularly high admission rates amongst conditions where very short hospital stays are commonplace (e.g. alcohol-related diseases, ENT infection, dehydration and gastroenteritis). PCTs with a larger proportion of day cases had increased admission rates for most ACSCs; this was particularly pronounced for ENT infections where areas with a high proportion had 183\% (95\% CI: 149, 222) more admissions than those with a low proportion. Unplanned admission rates for some ACSCs appear to be much less sensitive to population, practice and hospital characteristics. For example, hip fracture and stroke admission rates had little association with continuity of GP care, A\&E proximity or bed availability. 
Table 2 Characteristics of admitted patients by condition

\begin{tabular}{|c|c|c|c|c|c|}
\hline Condition & Mean Age & $\%$ Male & \% Most Deprived Quintile & $\%$ Admitted From GP & $\%$ Day Case \\
\hline Alcohol-related diseases & 43.8 & 68.0 & 40.1 & 4.3 & 35.4 \\
\hline Angina & 60.5 & 54.6 & 27.0 & 9.1 & 37.8 \\
\hline Asthma & 31.2 & 42.9 & 32.9 & 16.1 & 27.1 \\
\hline Atrial fibrillation / flutter & 56.3 & 40.7 & 21.4 & 12.6 & 41.0 \\
\hline Cellulitis & 51.6 & 52.1 & 27.4 & 26.6 & 22.5 \\
\hline Congestive heart failure & 78.5 & 51.6 & 22.9 & 19.8 & 6.9 \\
\hline Constipation & 51.4 & 42.6 & 27.6 & 27.0 & 32.4 \\
\hline Convulsions and epilepsy & 37.6 & 53.5 & 29.8 & 4.2 & 32.6 \\
\hline COPD & 71.2 & 48.3 & 33.5 & 15.6 & 12.1 \\
\hline Dehydration and gastro & 40.8 & 44.8 & 27.5 & 26.0 & 28.2 \\
\hline Dental condition & 35.1 & 51.8 & 31.8 & 11.8 & 27.2 \\
\hline Diabetes complications & 44.9 & 54.6 & 30.6 & 15.6 & 9.6 \\
\hline Dyspepsia / otr stomach function & 40.5 & 50.2 & 27.6 & 21.7 & 50.2 \\
\hline ENT infection & 10.2 & 52.9 & 30.8 & 34.2 & 53.0 \\
\hline Fractured proximal femur & 80.8 & 26.9 & 18.1 & 1.0 & 0.5 \\
\hline Hypertension & 60.9 & 41.3 & 25.7 & 26.3 & 35.5 \\
\hline Influenza and pneumonia & 67.5 & 51.2 & 24.7 & 17.0 & 7.5 \\
\hline Iron-deficiency anaemia & 65.0 & 38.8 & 25.8 & 37.0 & 20.0 \\
\hline Migraine / acute headache & 42.2 & 35.6 & 26.6 & 23.3 & 37.5 \\
\hline Neuroses & 47.6 & 44.0 & 31.2 & 7.4 & 30.6 \\
\hline Pelvic inflammatory disease & 32.6 & 0.0 & 30.7 & 24.5 & 15.1 \\
\hline Perforated / bleeding ulcer & 56.5 & 54.1 & 26.7 & 19.3 & 24.3 \\
\hline Peripheral vascular disease & 69.1 & 53.3 & 26.0 & 31.7 & 22.5 \\
\hline Pyelonephritis & 63.2 & 34.7 & 24.4 & 19.9 & 15.5 \\
\hline Ruptured appendix & 36.2 & 58.1 & 18.9 & 28.0 & 0.3 \\
\hline Schizophrenia & 42.5 & 63.0 & 45.3 & 2.6 & 4.8 \\
\hline Senility / dementia & 83.6 & 38.5 & 22.0 & 11.4 & 14.7 \\
\hline Stroke & 74.7 & 49.3 & 20.0 & 6.7 & 3.7 \\
\hline
\end{tabular}

\section{Discussion}

\section{Statement of principal findings}

ACSCs accounted for 1.77 million admissions and 10.9 million bed days during 2011/12. Admission rates were higher in practices located in deprived areas, within close proximity to an A\&E department, with poor continuity of GP care, and situated in areas with a high inpatient bed supply or proportion of day case admissions. There was little evidence that access to primary care, clinical quality, or practice size were important contributors to variation in unplanned admissions. The strength of associations differed markedly across conditions.

\section{Strengths and weaknesses}

This study is based on a large nationally representative dataset containing almost all unplanned admissions in England. Applying standardised and robust methodology to a broad range of ACSCs provides new evidence on the factors associated with admission rates, and allows identification of the characteristics that should be prioritised when redesigning services and developing admission avoidance interventions.

Our study is observational; although we have undertaken extensive case-mix adjustment it is still possible that our results are confounded by unmeasured factors. For example, it is possible that our finding of lower admission rates among practices with higher care continuity could be due, at least in part, to these practices better organising their care in other ways (e.g. support for self-care, specialist disease clinics). However, the negligible associations for conditions where admission is not usually avoidable (e.g. hip fracture) suggests that residual confounding is not solely driving our results. Some of the characteristics considered within our study may be poorly measured. 
Table 3 Difference in unplanned admissions between a high (90th centile) and low (10th centile) practice for selected conditions ${ }^{a}$

\begin{tabular}{|c|c|c|c|c|c|c|c|c|}
\hline & $\begin{array}{l}\text { All ACSCs } \\
\text { Combined }\end{array}$ & $\begin{array}{l}\text { Alcohol- Related } \\
\text { Diseases }\end{array}$ & COPD & $\begin{array}{l}\text { Dehydration } \\
\text { and Gastro }\end{array}$ & ENT Infections & Hypertension & Hip Fracture & Stroke \\
\hline \multicolumn{9}{|c|}{ Practice characteristics } \\
\hline Deprivation & $16(14,18)$ & $44(35,54)$ & $36(30,42)$ & $8(5,11)$ & $7(3,12)$ & $7(-5,20)$ & $7(3,11)$ & $12(8,16)$ \\
\hline \multicolumn{9}{|l|}{ A\&E Distance } \\
\hline Furthest Away & Ref & Ref & Ref & Ref & Ref & Ref & Ref & Ref \\
\hline 2nd Quartile & $5(4,6)$ & $9(3,15)$ & $6(2,10)$ & $8(5,10)$ & $4(0,7)$ & $3(-6,12)$ & $-1(-3,2)$ & $3(0,5)$ \\
\hline 3rd Quartile & $7(5,8)$ & $15(8,23)$ & $10(6,14)$ & $9(6,12)$ & $4(0,8)$ & $8(-2,19)$ & $-1(-4,1)$ & $1(-2,4)$ \\
\hline Closest & $8(7,10)$ & $21(13,29)$ & $10(5,14)$ & $14(11,17)$ & $11(7,16)$ & $12(2,24)$ & $-3(-6,-0)$ & $2(-1,5)$ \\
\hline Continuity & $-9(-11,-8)$ & $-7(-11,-2)$ & $-13(-16,-10)$ & $-7(-9,-5)$ & $-10(-13,-7)$ & $-20(-26,-13)$ & $-0(-3,3)$ & $-2(-5,0)$ \\
\hline Access & $-1(-2,0)$ & $1(-3,6)$ & $-1(-4,2)$ & $-2(-4,0)$ & $-0(-3,2)$ & $-2(-9,5)$ & $1(-1,4)$ & $2(-1,4)$ \\
\hline Quality & $-2(-3,-1)$ & $-4(-7,-1)$ & $-1(-3,1)$ & $-1(-3,0)$ & $-3(-5,-1)$ & $-4(-10,2)$ & $1(-1,3)$ & $-1(-3,1)$ \\
\hline Size & $-2(-3,-1)$ & $2(-3,6)$ & $0(-3,3)$ & $-1(-3,1)$ & $1(-2,4)$ & $-1(-8,6)$ & $2(0,4)$ & $0(-2,2)$ \\
\hline \multicolumn{9}{|l|}{ PCT characteristics } \\
\hline Bed Availability & $12(8,17)$ & $39(21,60)$ & $16(9,23)$ & $24(16,32)$ & $25(12,41)$ & $24(9,40)$ & $-1(-4,2)$ & $5(1,9)$ \\
\hline$\%$ Day Cases & $17(12,21)$ & $12(-3,29)$ & $9(4,14)$ & $28(20,37)$ & $183(149,222)$ & $1(-11,14)$ & $0(-3,3)$ & $2(-1,6)$ \\
\hline
\end{tabular}

${ }^{a}$ After adjustment age, sex and chronic disease prevalence (atrial fibrillation, asthma, cancer, CKD, COPD, dementia, epilepsy, heart failure, hypertension, learning disability, mental health problems, obesity and stroke) and each of the factors listed in the table

Specifically, QOF clinical scores may not accurately reflect primary care quality [13], the IMD of a practice postcode may not accurately reflect the socioeconomic status of their registered patients [14], straight line distances to A\&E departments may be a poor measure of travel times [15], and our surveybased estimates of primary care access and continuity may be imprecise. This measurement error is likely to have led us to underestimate the association between unplanned admission rates and each of the variables included within our analysis due to regression dilution bias [16].

Admission rates for mental health conditions may be inaccurate [17]. Although mental health trusts report data to HES, a range of community-based alternatives (e.g. crisis houses) may substitute for hospital treatment

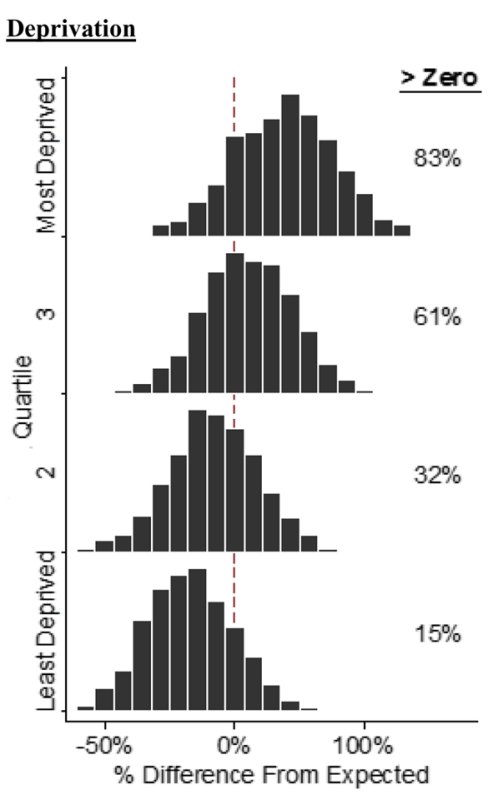

\section{A\&E Proximity}

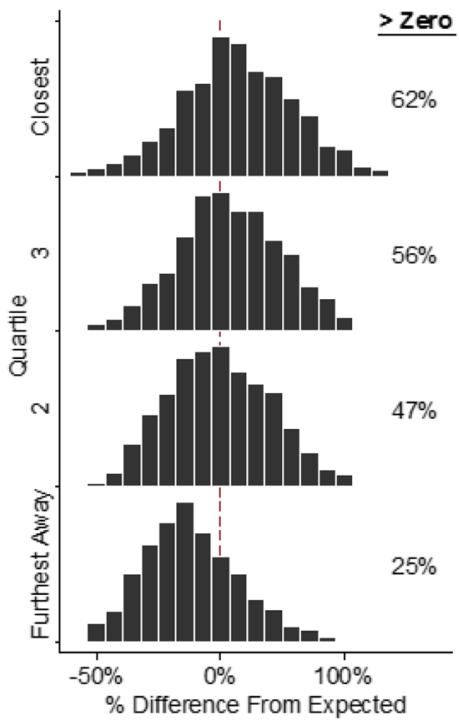

Fig. 1 Distribution of hospital admission rates, adjusted for age and sex. Dotted red line represents where the number of observed admissions matches the number that would be expected given the size and age-sex composition of the practice 


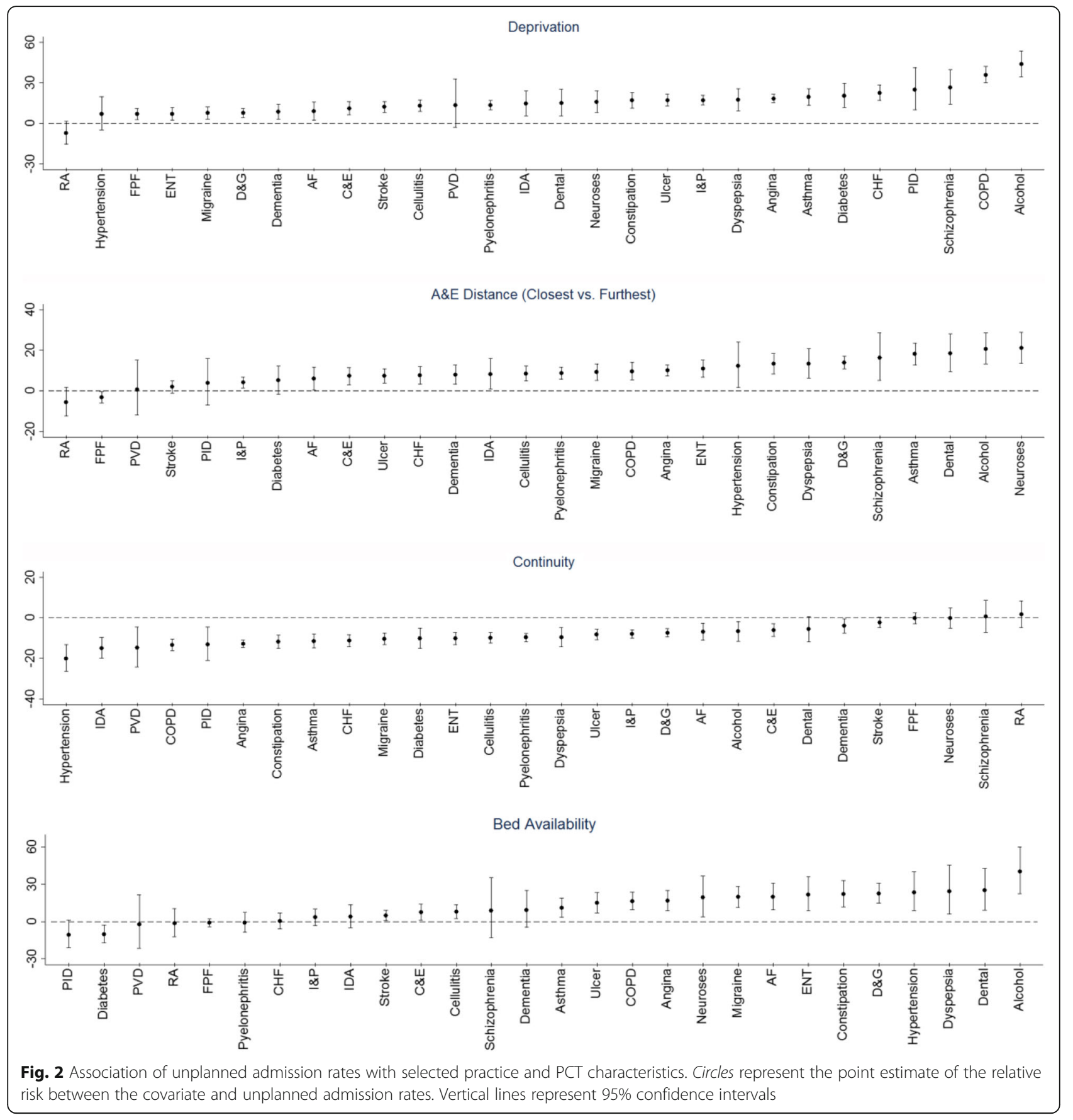

and are not included in the dataset. Our findings of a very strong association between ENT infection admission rates and the proportion of day case admissions may be explained by variable recording of clinical decision unit activity across hospitals, or the availability of alternatives to short-stay admission (e.g. ENT 'hot' clinics) in some trusts [1]. Our study does not include information on patient outcomes or resource use outside hospital which prohibits identification of the 'optimal' admission rate.

\section{Comparison with other studies}

Several studies have identified the crucial role that deprivation and A\&E proximity play in driving unplanned ACSC admission rates [9]. There is a growing body of evidence that improved continuity of primary care is associated with lower unplanned ACSC admission rates [9]. For example, one English study found admissions reduced by $0.5 \%$ per percentage point increase in the number of patients able to book with a specific GP [18]. Strong associations between inpatient 
bed availability and unplanned ACSC admission rates have been detailed elsewhere $[10,19]$, including in a UK study which found that patients resident in areas with the highest quintile of hospital beds had 13-15\% higher respiratory disease admission rates than those within the lowest quintile [19].

A recent systematic review found little evidence of reduced unplanned ACSC admission rates among practices with better appointment availability within the UK or Europe [9]. Several studies investigating the association between QOF scores and unplanned admission rates have found little or no association except for a few specific conditions (e.g. COPD, CHD) [20]. There is negligible evidence that unplanned admission rates differ by general practice size [9].

\section{Implications for clinicians and policymakers}

Increasing unplanned admission rates are an important problem facing healthcare systems worldwide. Addressing the variance in continuity of GP care, finding and publicising convenient alternatives to admission for patients registered at practices closest to $\mathrm{A} \& \mathrm{E}$, and reducing the number of short-stay admissions are potential components of successful admission avoidance interventions. Our results suggest that the success of each of these strategies is likely to vary by condition and that a multifaceted programme of interventions, tailored to local problems, is required to contain secondary care demand and reduce costs. Some of the characteristics investigated in this study are not readily modified (e.g. deprivation) or are largely beyond the control of GPs (e.g. local hospital bed availability, A\&E proximity). Failure to account for these during routine audit or benchmarking could undermine efforts to detect and manage poorer quality primary care. Given the results of our study, it is likely that distinct adjustment models will be required for each condition to guard against residual confounding.

Continuity of care is an important facet of primary care, particularly for chronic conditions such as hypertension, COPD and CHF which often rely on frequent primary care management and co-occur with other morbidities. If the assocations observed in our study are causal, nearly 100,000 ACSC admissions could be avoided by practices annually through providing 'good continuity' care (defined being able to see or speak to their preferred GP 'Always,' Almost always' or 'A lot of the time' to the question) to $90 \%$ of their registered patients. Assuming an average ACSC admission cost of $£ 1,739$ [21], this would equate to hospital savings of around $£ 170$ million. Improved continuity would most obviously be attained through a growth in GP numbers, although this is likely to be challenging due to ongoing GP recruitment issues in many countries [22]. Other practice-level changes such as patient education, empowering patients to trade-off GP choice and speed of access, and better practitioner communication might be more easily achieved [23].

Our findings do not support recent UK government initiatives that focus on improvements in primary care access [24], particularly if these are implemented to the detriment of the continuity of care. A UK-based review investigating the link between primary care access and unplanned admission rates concluded that 'Existing evidence...is inadequate to inform national policy' [25]. Our results concur with this finding and suggest that a fuller investigation of the benefits and costs of increased access is required before implementation. The small and inconsistent association between clinical quality scores and admission rates suggests that this crude measure of primary care quality may not adequately encompass the most important aspects of GP care for averting unplanned ACSC admissions. The extent to which the care processes that the QOF incentivises lead to improvements in patient outcomes has generated substantial debate [26] and continues to evolve. The latest evidence suggests the QOF has been responsible for an $8 \%$ reduction in unplanned admission rates for incentivised ACSCs [27].

ACSC admission rates may be higher in some areas due to the increased frequency of very short admissions. Nationally, the number of short-stay admission has surged by $124 \%$ in the last 15 years [1] however our results suggest substantial geographic variation in their use. Some short hospital stays are clinically appropriate (e.g. severe exacerbations of asthma), however others may result from inappropriate referrals, limited community-based care options, patient confusion around out-of-hours care arrangements, or government targets (e.g. 4-hour A\&E waits) [1]. Improved referral guidelines, enhanced community-based treatment options (e.g. telemedicine) or increased accessibility and awareness of alternatives to $A \& E$ attendance (e.g. walkin clinics) might reduce these admissions, although there remains little research exploring their affect on overall healthcare outcomes and costs [28]. The strong influence exerted by inpatient bed availability and A\&E proximity on admission rates suggests that some ACSC care may be 'supply sensitive' [29].

\section{Unanswered questions and future research}

Randomised controlled trials examining the effect of new interventions to improve the continuity of primary care are required. Evaluation of community-based interventions (e.g. improved self-management) aimed at preventing unnecessary hospital admissions are needed, particularly in deprived areas and those within close proximity to A\&E. 


\section{Conclusions}

Increasing unplanned hospital admissions is a key problem facing healthcare systems worldwide. The drivers of high unplanned ACSC admission rates are complex and include population (e.g. higher deprivation), practice (e.g. poor continuity of care) and hospital (e.g. increased inpatient bed availability) factors. The importance of these varies substantially across conditions suggesting multifaceted interventions are required to improve care and reduce costs. Several of the most important drivers of admissions are beyond the control of GPs. Strategies to increase the continuity of primary care and avoid unnecessary short-stay admissions could reduce admissions; however a fuller understanding of how these interventions affect aggregate healthcare costs and patient outcomes is required.

\section{Additional files}

Additional file 1: Included ACSCS and ICD-10 codes used to define them. List of ICD-10 codes used to identify admissions for each of the conditions used within the analysis. (DOCX $39 \mathrm{~kb}$ )

Additional file 2: Independent variable description, potential weaknesses and source. Description of each independent variable used in the analysis. (DOCX $46 \mathrm{~kb}$ )

Additional file 3: Calculation of age-sex specific GP population. Description of how the age-sex specific GP practice populations were determined. (DOCX $37 \mathrm{~kb}$ )

Additional file 4: Association of unplanned admission rates with selected practice and PCT characteristics. Graphical representation of association between primary care access, primary care quality, practice size and percentage of day case admissions with unplanned ACSC admission rates. (DOCX $203 \mathrm{~kb}$ )

\section{Abbreviations}

A\&E: Accident and emergency; ACSC: Ambulatory care sensitive condition; CHD: Coronary heart disease; COPD: Chronic obstructive pulmonary disease; ENT: Ear, nose throat; HES: Hospital episode statistics; IMD: Index of multiple deprivation; NHS: National health service; PCT: Primary care trust; QOF: Quality and outcomes framework

\section{Acknowledgements}

None.

\section{Funding}

None to declare.

\section{Availability of data and materials}

The data that support the findings of this study are available from The Health \& Social Care Information Centre but restrictions apply to the availability of these data, which were used under license for the current study, and so are not publicly available. Data are however available from the authors upon reasonable request and with permission of The Health \& Social Care Information Centre.

\section{Authors' contributions}

All authors conceived the study. JB conducted the analysis and drafted the manuscript. WH and SP critically revised the article for intellectual content. All authors read and approved the final manuscript. All authors had full access to the data in the study and can take responsibility for the integrity of the data and the accuracy of the data analysis.

\section{Competing interests}

The authors declare that they have no competing interests.

\section{Consent for publication}

Not applicable.

Ethics approval and consent to participate

Our study did not require ethnical approval as it was based on non-identifiable data previously collected in the course of routine care.

\section{Publisher's Note}

Springer Nature remains neutral with regard to jurisdictional claims in published maps and institutional affiliations.

\section{Author details}

${ }^{1}$ Centre for Public Health, Queen's University Belfast, BT12 6BA, Belfast, UK. ${ }^{2}$ School of Social and Community Medicine, University of Bristol, BS8 2PS, Bristol, UK.

Received: 6 January 2017 Accepted: 11 May 2017

Published online: 25 May 2017

\section{References}

1. Department of Health. Emergency admissions to hospital: managing the demand. London: Department of Health; 2013.

2. Caesar U, Karlsson J, Olsson LE, Samuelsson K, Hansson-Olofsson E. Incidence and root causes of cancellations for elective orthopaedic procedures: a single centre experience of 17,625 consecutive cases. Patient Saf Surg. 2014;8:24.

3. Robinson P. Are emergency admissions in England Out of control? 2010.

4. Quality Premium. http://www.england.nhs.uk/ccg-ois/qual-prem/. Accessed 21 Apr 2016.

5. Blunt I. Focus on preventable admissions. London: Nuffield Trust; 2013.

6. Purdy S, Griffin T, Salisbury C, Sharp D. Ambulatory care sensitive conditions: terminology and disease coding need to be more specific to aid policy makers and clinicians. Public Health. 2009;123(2):169-73.

7. Busby J, Purdy S, Hollingworth W. Using geographic variation in unplanned ambulatory care sensitive condition admission rates to identify commissioning priorities: an analysis of routine data from England. J Health Serv Res Policy. 2016;22:20-7.

8. Busby J, Purdy S, Hollingworth W. Opportunities for primary care to reduce hospital admissions: a cross-sectional study of geographical variation. $\mathrm{Br}$ J Gen Pract. 2017;67:e20-e8.

9. Huntley A, Lasserson D, Wye L, Morris R, Checkland K, England H, Salisbury C, Purdy S. Which features of primary care affect unscheduled secondary care use? A systematic review. BMJ Open. 2014;4(5):e004746.

10. Busby J, Purdy S, Hollingworth W. A systematic review of the magnitude and cause of geographic variation in unplanned hospital admission rates and length of stay for ambulatory care sensitive conditions. BMC Health Serv Res. 2015;15(1):1-15.

11. Numbers of Patients Registered at a GP Practice - April 2013. https://data. england.nhs.uk/dataset/numbers-of-patients-registered-at-a-gp-practiceapril-2013. Accessed 21 Apr 2016.

12. Quality and Outcomes Framework. http://www.hscic.gov.uk/qof. Accessed 21 Apr 2016.

13. Langdown C, Peckham S. The use of financial incentives to help improve health outcomes: is the quality and outcomes framework fit for purpose? A systematic review. J Public Health (Oxf). 2014;36(2):251-8.

14. Strong M, Maheswaran R, Pearson T. A comparison of methods for calculating general practice level socioeconomic deprivation. Int J Health Geogr. 2006;5(1):1-5

15. Haynes $R$, Jones AP, Sauerzapf $V$, Zhao $H$. Validation of travel times to hospital estimated by GIS. Int J Health Geogr. 2006;5(1):40.

16. Hutcheon JA, Chiolero A, Hanley JA. Random measurement error and regression dilution bias. BMJ. 2010;340:c2289.

17. White J, Gutacker N, Jacobs R, Mason A. Hospital admissions for severe mental illness in England: Changes in equity of utilisation at the small area level between 2006 and 2010. Soc Sci Med. 2014;120:243-51.

18. Bankart MJG, Baker R, Rashid A, Habiba M, Banerjee J, Hsu R, Conroy S, Agarwal S, Wilson A. Characteristics of general practices associated with emergency admission rates to hospital: a cross-sectional study. Emerg Med J. 2011;28(7):558-63. 
19. Purdy S, Griffin T, Salisbury C, Sharp D. Emergency respiratory admissions: influence of practice, population and hospital factors. J Health Serv Res Policy. 2011;16(3):133-40.

20. Gillam SJ, Siriwardena AN, Steel N. Pay-for-performance in the United Kingdom: impact of the quality and outcomes framework: a systematic review. Ann Fam Med. 2012;10(5):461-8.

21. The Kings Fund. Data briefing: emergency hospital admissions for ambulatory care-sensitive conditions: identifying the potential for reductions. 2012.

22. Verma P, Ford JA, Stuart A, Howe A, Everington S, Steel N. A systematic review of strategies to recruit and retain primary care doctors. BMC Health Serv Res. 2016;16(1):126.

23. The Kings Fund. Continuity of care and the patient experience. 2010.

24. Seven-day a week NHS: Prime Minister's visit and speech. https://www.gov. uk/government/news/seven-day-a-week-nhs-prime-ministers-speech. Accessed 21 Apr 2016.

25. Cowling TE, Harris MJ, Majeed A. Evidence and rhetoric about access to UK primary care. BMJ. 2015;350:h1513.

26. Gillam S, Steel N. The Quality and Outcomes Framework—where next?. BMJ. 2013;346. http://www.bmj.com/content/346/bmj.f659.

27. Harrison MJ, Dusheiko M, Sutton M, Gravelle H, Doran T, Roland M. Effect of a national primary care pay for performance scheme on emergency hospital admissions for ambulatory care sensitive conditions: controlled longitudinal study. BMJ. 2014;349:96423.

28. Purdy S. Avoiding hospital admissions: What does the research evidence say? London: The Kings Fund; 2010

29. Fisher ES, Wennberg JE. Health care quality, geographic variations, and the challenge of supply-sensitive care. Perspect Biol Med. 2003;46(1):69-79.

\section{Submit your next manuscript to BioMed Central and we will help you at every step:}

- We accept pre-submission inquiries

- Our selector tool helps you to find the most relevant journal

- We provide round the clock customer support

- Convenient online submission

- Thorough peer review

- Inclusion in PubMed and all major indexing services

- Maximum visibility for your research

Submit your manuscript at www.biomedcentral.com/submit

) Biomed Central 